\title{
Delamination effects on cracked steel members reinforced by prestressed composite patch
}

\author{
P. Colombi ${ }^{\mathrm{a}, *}$, A. Bassetti ${ }^{\mathrm{b}}$, A. Nussbaumer ${ }^{\mathrm{b}}$ \\ a Department of Structural Engineering, Milan Technical University, Piazza L. da Vinci, 32, 20133 Milan, Italy \\ ${ }^{\mathrm{b}}$ ICOM-Institute of Steel Construction, Swiss Federal Institute of Technology, EPFL Lausanne, Switzerland
}

\begin{abstract}
Prestressed composite patch bonded on cracked steel section is a promising technique to reinforce cracked details or to prevent fatigue cracking on steel structural elements. It introduces compressive stresses that produce crack closure effect. Moreover, it modifies the crack geometry by bridging the crack lips and reduces the stress range at crack tip. Fatigue tests were performed on notched steel plate reinforced by CFRP strips as a step toward the validation of crack patching for fatigue life extension of riveted steel bridges. A debond crack in the adhesive-plate interface was observed by optical technique. Debond crack total strain energy release rate is computed by the modified virtual crack closure technique. A parametric analysis is performed in order to investigate the influence of some design parameters such as the composite patch Young's modulus, the adhesive thickness and the pretension level on the adhesive-plate interface debond.
\end{abstract}

(c) 2003 Elsevier Science Ltd. All rights reserved.

Keywords: Composite patch reinforcement; Debond crack; Strain energy release rate

\section{Introduction}

Cracked aluminium structures reinforced by composite patches is a standard procedure in aircraft industry [1]. Such application can be found in the automotive industry where the structural elements are also subjected to extreme high fatigue loads, high temperature ranges and exposure to aggressive environments. Composite materials are bonded to thin metallic elements [2]. Carbon fibre laminates (CFRP) have also been used in civil

\footnotetext{
${ }^{*}$ Corresponding author. Tel.: +390-2-2399-42089; fax: +3902-2399-4220.

E-mail address: colombi@stru.polimi.it (P. Colombi).
}

engineering applications. The reinforcement of concrete bridges with CFRP laminates was made [3]. It was shown that composites bonded with epoxy resins are a reliable solution for bridges strengthening. Very high tensile strength composite materials could be employed in order to prestress the CFRP laminates [4]. More recently, attempts were done to reinforce metallic structures in civil engineering with composite materials in order to increase the load carrying capacity of the steel bridges sections [5]. CFRP patching, which could be prestressed prior to bonding, was proposed in [6-11] as a way for reinforcing steel structural elements damaged by fatigue. The high fatigue resistance of CFRP avoids crack propagation from the cracked steel section into the 
patch. The high stiffness of CFRP reduces the stress range in the cracked steel section and promotes crack bridging. The effectiveness of this technique was shown by fatigue tests on notched steel plates reinforced by CFRP strips. Several fatigue tests on cross-girders taken from a dismantled riveted steel bridge, reinforced by CFRP strips, were also performed in order to show the applicability to bridge reinforcement [6-11].

High fatigue resistance of CFRP laminates prevents fatigue crack propagation in the composite patch but a debonded region is created between the steel plate and the patch. This debond area may propagate in the adhesive-plate or adhesive-patch interface. This growth is due to the high stress concentration in the cracked plate. The evaluation of mode I and mode II strain energy release rates $[12,13]$ was carried out in the literature in order to provide a fracture criterion for interfacial cracks. The bi-material interface crack always induces both opening and shearing mode behaviour even if the load is symmetric [14]. The stress field also possesses a physically inadmissible oscillatory character that is confined to small stress region near the end of the crack. The strain energy release per unit area for the extension of the crack over a short distance, $\Delta a$, could be computed. It is well known that the strain energy release rates for mode I, $G_{\mathrm{I}}$, and mode II, $G_{\mathrm{II}}$, separately are theoretically non-existent [14] since they are not defined as $\Delta a$ goes to zero. However, for finite crack extension, $\Delta a$, the individual strain energy release rates exist and could be used [15] to study delamination crack growth. Alternatively, the total strain energy release rate, $G$, has been used as a fracture parameter for interfacial crack propagation [16]. Adding $G_{\mathrm{I}}$ and $G_{\mathrm{II}}$, however, gives rise to conceptual difficulties because mode I and mode II do not grow in the same direction. A more plausible criterion physically is that of the strain energy density approach $[17,18]$. It models crack extension as a discrete process instead of a continuous process. It should also be kept in mind that the application of the method of virtual work requires the work done to be a minimum. More discussion on this can be found in the conclusion. In what follows, reference is made to the notched steel plate fatigue tests performed in [6-11]. Numerical analyses show that the size of the debonded region is influenced by the efficiency of the crack repair. The objective of this work is twofold: first to evaluate the $G$ distribution along the crack growth induced debond front and second to study the influence of some design parameters such as the composite patch Young's modulus, the adhesive thickness and the pretension level on the adhesiveplate interface debond. A suitable bi-dimensional finite element model based on the three-layer technique [13] is developed to compute debond crack strain energy release rate by the modified virtual crack closure technique (MVCCT) in [19].

\section{Reinforcement of steel members by prestressed CFRP strips}

The effectiveness of CFRP strips or laminates to reduce or to arrest crack propagation is investigated by fatigue tests on notched steel plate (Fig. 1).

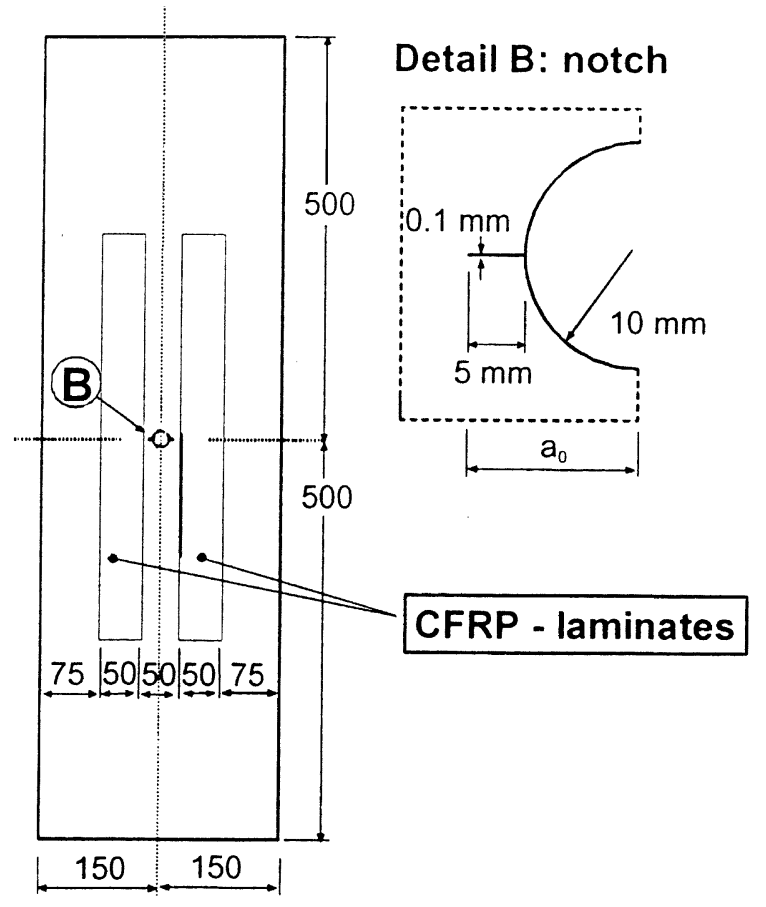

Fig. 1. Test specimen. 
Table 1

Material properties and dimensions

\begin{tabular}{lccll}
\hline Layer & $\begin{array}{l}\text { Length } \\
(\mathrm{mm})\end{array}$ & $\begin{array}{l}\text { Width } \\
(\mathrm{mm})\end{array}$ & $\begin{array}{l}\text { Thickness } \\
(\mathrm{mm})\end{array}$ & Material properties \\
\hline Steel plate & 1000 & 300 & 10 & $E_{\mathrm{s}}=210 \mathrm{GPa}, v_{\mathrm{s}}=0.3$ \\
Adhesive & 500 & 50 & 0.3 & $E_{\mathrm{a}}=714.14 \mathrm{MPa}, v_{\mathrm{a}}=0.32$ \\
CFRP patch & 500 & 50 & 1.2 & $\begin{array}{l}E_{1}=174 \mathrm{GPa}, E_{2}=9 \mathrm{GPa}, v_{12}=0.28, G_{12}=G_{13}=4.5 \mathrm{GPa}, \\
\end{array}$ \\
\end{tabular}

The central notch consists of a hole and two initial cracks produced by electroerosion. Hole diameter and plate thickness are representative of rivet holes and plates thickness used in riveted members since the long term objective of this work is to show the applicability of such a reinforcement technique to riveted steel bridges. The notched steel plates are reinforced on both sides with two CFRP strips. The material properties and dimensions of the specimen are reported in Table 1.

The application of composite strips to steel plate does not produce a significant reduction of the stress levels since the stiffness of the steel plate is much larger than that of the composite strips. In order to increase the effectiveness of the patch reinforcement, the CFRP strips must then be prestressed as shown in [6-11]. Prestressing of the CFRP strips introduces compressive stresses that promote crack closure effect [20]. In this work reference is made to fatigue tests on notched steel plate with a constant amplitude load range $\Delta F=240 \mathrm{kN}$ and a load ratio $F_{\min } / F_{\max }=0.4$. Since the thickness of the adhesive $(0.3 \mathrm{~mm})$ is much smaller than the steel plate $(10$ $\mathrm{mm})$ and the composite strips $(1.2 \mathrm{~mm})$, a threedimensional analysis becomes very expensive. A bi-dimensional model is then adopted in connection with the MVCCT to evaluate the debond crack strain energy release rate.

\subsection{Experimental evidence}

As the crack approaches the interior boundary of the strip, high stress concentration at the crack tip produces debond at the plate-adhesive or adhesive-patch interface. From the inspection of the failed specimens, debond was found to be present between the steel plate and the adhesive layer. Debond was investigated in [6-11] by Optical Speckle Interferometry technique [21]. The evolution of the displacement field at the specimen surface is reported in Fig. 2.

Each fringe represents a displacement of $1.3 \mu \mathrm{m}$ in the longitudinal direction. At the beginning of the test, Fig. 2(a), no relative displacement is present between the steel plate and the adhesive layer. As the crack in the steel plate approach the external boundary of the composite strip, Fig. 2(b) relative displacements are present between the steel plate and the adhesive layer. Moreover, the deformation level in the composite strip is increased.

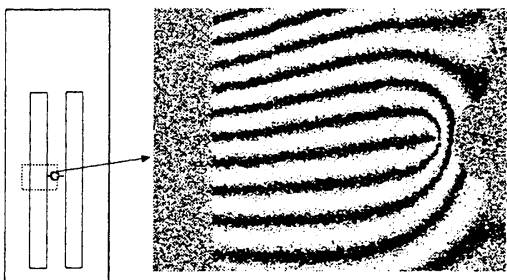

a) $\mathrm{N}=0$

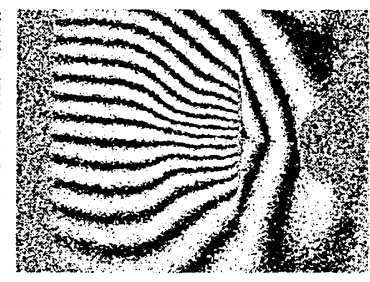

b) $\mathrm{N}=650000$

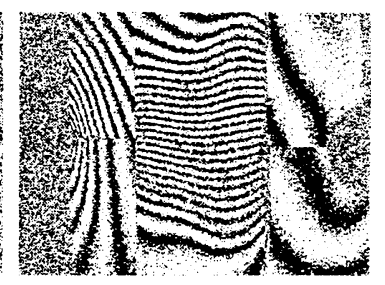

c) $\mathrm{N}=1200000$

Fig. 2. Displacements field on specimen surface by Optical Speckle Interferometry. 
At the end of the test, Fig. 2(c), the fatigue crack is outside the patch and the boundary of the delamination zone is parallel to the crack. The form and dimensions of the debonded zones are deduced by comparing the displacement field obtained by finite elements calculations with the experimental one [6-11]. The results showed that debond zone between adhesive layer and steel plate is well approximated by an ellipse with an aspect ratio $c / b$ of $1 / 5$. The delamination front is supposed to be ahead the crack tip at a distance equal to the plastic zone.

\section{Numerical model}

\subsection{Three-layer technique}

In [13] the three-layer technique is used to model a composite bonded reinforced cracked plate. This technique uses two-dimensional finite element analysis, consisting of three layers, to model the steel plate, adhesive layer and composite patch. It is not required to replace the adhesive layer by shear spring elements (non-continuum body) [12,22] since the adhesive layer is modelled as an elastic continuum medium. In this way the characteristics of the adhesive required to model non-linear material behaviour are also captured. Constraints are used to enforce the compatibility along the plateadhesive and the adhesive-patch interface based on Mindlin assumptions (Fig. 3).

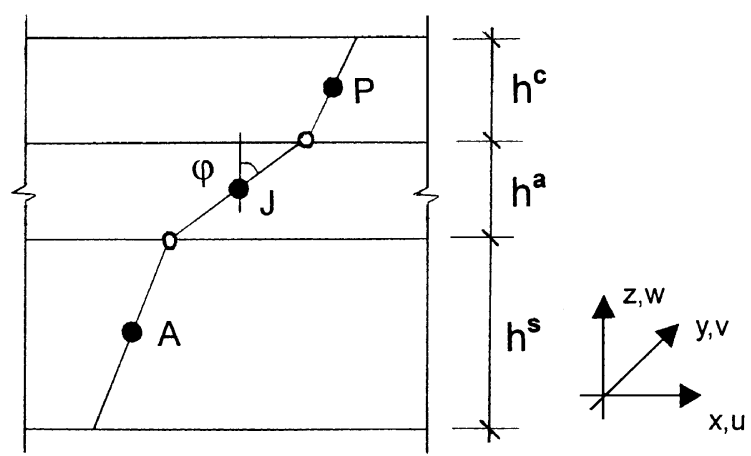

Fig. 3. Modelling of bonded reinforcement.
According to Mindlin plate theory (Fig. 3), all three layers, steel plate, adhesive and composite patch, are assumed to have a linear displacements field along the thickness and they satisfy the relations [13]:

$$
\begin{aligned}
& u^{\mathrm{c}}=u_{P}+\varphi_{y}^{P} \cdot z^{\mathrm{c}}, \quad u^{\mathrm{a}}=u_{J}+\varphi_{y}^{J} \cdot z^{\mathrm{a}}, \quad u^{\mathrm{s}}=u_{A}+\varphi_{y}^{A} \cdot z^{\mathrm{s}} \\
& v^{\mathrm{c}}=v_{P}+\varphi_{x}^{P} \cdot z^{\mathrm{c}}, \quad v^{\mathrm{a}}=v_{J}+\varphi_{x}^{J} \cdot z^{\mathrm{a}}, \quad v^{\mathrm{s}}=v_{A}+\varphi_{x}^{A} \cdot z^{\mathrm{s}} \\
& w^{\mathrm{c}}=w_{P}, \quad w^{\mathrm{a}}=w_{J}, \quad w^{\mathrm{s}}=w_{A}
\end{aligned}
$$

where the superscript $\mathrm{s}$, a and $\mathrm{c}$ are used to denote the steel plate, adhesive layer and composite patch, respectively. The co-ordinates $z^{\mathrm{c}}, z^{\mathrm{a}}$ and $z^{\mathrm{s}}$ are measured from the midplane of each layer. Making use of Eq. (1), at the plate-adhesive interface, where the $z$ co-ordinates for the cracked plate and the adhesive layer are equal, the constraint equations reduce to

$$
\begin{aligned}
& u^{\mathrm{a}}=u^{\mathrm{s}} \Rightarrow u_{J}-u_{A}-\varphi_{y}^{J} \cdot \frac{h^{\mathrm{a}}}{2}-\varphi_{y}^{A} \cdot \frac{h^{\mathrm{s}}}{2}=0 \\
& v^{\mathrm{a}}=v^{\mathrm{s}} \Rightarrow v_{J}-v_{A}+\varphi_{x}^{J} \cdot \frac{h^{\mathrm{a}}}{2}+\varphi_{x}^{A} \cdot \frac{h^{\mathrm{s}}}{2}=0 \\
& w^{\mathrm{a}}=w^{\mathrm{s}}
\end{aligned}
$$

and at the adhesive-patch interface, where the $z$ co-ordinates for the adhesive layer and the composite patch are equal. Hence,

$$
\begin{aligned}
& u^{\mathrm{c}}=u^{\mathrm{a}} \Rightarrow u_{P}-u_{J}-\varphi_{y}^{P} \cdot \frac{h^{\mathrm{c}}}{2}-\varphi_{y}^{J} \cdot \frac{h^{\mathrm{a}}}{2}=0 \\
& v^{\mathrm{c}}=v^{\mathrm{a}} \Rightarrow v_{P}-v_{J}+\varphi_{x}^{P} \cdot \frac{h^{\mathrm{c}}}{2}+\varphi_{x}^{J} \cdot \frac{h^{\mathrm{a}}}{2}=0 \\
& w^{\mathrm{c}}=w^{\mathrm{a}}
\end{aligned}
$$

The three-layer rotations are independent of each other and only use of displacement constraint at the interfaces to enforce geometric compatibility is required. In the debonded region between the steel plate and the adhesive layer, the layers are independent of each other and the constraint equations are no longer valid. Note that due to the symmetry of the reinforcement no overlapping due to translation in the thickness direction is possible.

\subsection{Strain energy release rate}

The MVCCT [19] is used to calculate the strain energy release rate along the debond front. This 
technique allows calculation of the strain energy release rate in a single analysis [23]. Consider the schematic three-layer model in Fig. 4.

A four-node Mindlin plate element is used to model the adhesive layer and composite strips. Due to the symmetry, a four-node plane stress element is used to model the steel plate. The idea is to calculate the strain energy release per unit area for the extension of the crack over a short distance $\triangle a$. According to the MVCCT, the generalised forces are evaluated at node $B$. Since the extension $\Delta a$ is very small, the crack opening displacements at $B$ are assumed to be the same as those at $A$. The forces and moments are evaluated by finite element method in the midplane of each layer. They are equal to the static quantities associated with constraints and are computed by summing up the contributions of nodal forces and moments at that node from every element at the node. The strain energy release is evaluated as

$$
\begin{aligned}
& W^{\mathrm{TOT}}=W_{x}^{B K}+W_{y}^{B K}+W_{z}^{B K}, \\
& W_{x}^{B K}=\frac{1}{2}\left(F_{x}^{B} \cdot \Delta u\right) ; \quad W_{y}^{B K}=\frac{1}{2}\left(F_{y}^{B} \cdot \Delta v\right) ; \\
& W_{z}^{B K}=\frac{1}{2}\left(F_{z}^{B} \cdot \Delta w\right)
\end{aligned}
$$

where $F_{x}, F_{y}$ and $F_{z}$ are the interface forces in the $x, y$ and $z$ direction, respectively, while $\Delta u, \Delta v$ and $\Delta w$ are the relative displacements between the steel plate and the adhesive layer (Fig. 4). Consider first the contribution to strain energy release in the $x$ direction, $W_{x}^{B K}$. The constraint forces between the nodes satisfy the following equilibrium equations:

$$
\begin{aligned}
& F_{x}^{B}+F_{x}^{K}+F_{x}^{Q}=0 \\
& F_{x}^{Q} \cdot \frac{h^{\mathrm{c}}}{2}+M_{y}^{Q}=0 \\
& F_{x}^{Q} \cdot \frac{h^{\mathrm{a}}}{2}-F_{x}^{B} \cdot \frac{h^{\mathrm{a}}}{2}+M_{y}^{k}=0 \\
& F_{x}^{B} \cdot \frac{h^{\mathrm{s}}}{2}-M_{y}^{B}=0
\end{aligned}
$$

The relative interface displacement in the $x$ direction is given by

$$
\Delta u=u_{A}-u_{J}+\varphi_{y}^{J} \cdot \frac{h^{\mathrm{a}}}{2}+\varphi_{y}^{A} \frac{h^{\mathrm{s}}}{2}
$$

The strain energy release contribution is given by

$$
\begin{aligned}
W_{x}^{B K} & =\frac{1}{2}\left(F_{x}^{B} \Delta u\right) \\
& =\frac{1}{2}\left[F_{x}^{B} u_{A}-F_{x}^{B} u_{J}+F_{x}^{B} \frac{h^{\mathrm{a}}}{2} \varphi_{y}^{J}+F_{x}^{B} \frac{h^{\mathrm{s}}}{2} \varphi_{y}^{A}\right]
\end{aligned}
$$

Making use of the equilibrium equations (Eq. (5)) and the constraint (nodes $J$ and $P$ are tied), there results

$u_{J}=u_{P}-\varphi_{y}^{P} \frac{h^{\mathrm{c}}}{2}-\varphi_{y}^{J} \frac{h^{\mathrm{a}}}{2}$

and the contribution $W_{x}^{B K}$ to the strain energy release is

$$
\begin{aligned}
W_{x}^{B K}= & \frac{1}{2}\left[F_{x}^{B} u_{A}+M_{y}^{B} \varphi_{y}^{A}+F_{x}^{K} u_{J}+M_{y}^{K} \varphi_{y}^{J}\right. \\
& \left.+F_{x}^{Q} u_{P}+M_{y}^{Q} \varphi_{y}^{P}\right]
\end{aligned}
$$

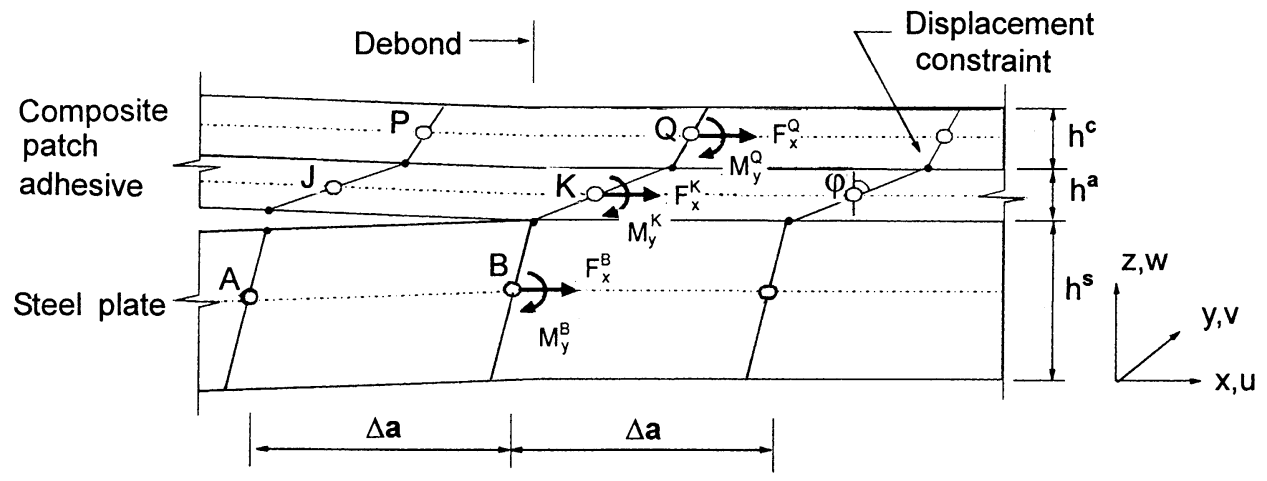

Fig. 4. Schematic three layers model for delaminated plate. 
In a similar way, the contributions $W_{y}^{B K}$ and $W_{z}^{B K}$ are found:

$$
\begin{aligned}
W_{y}^{B K}= & \frac{1}{2}\left[F_{y}^{B} v_{A}+M_{x}^{B} \varphi_{x}^{A}+F_{y}^{K} v_{J}+M_{x}^{K} \varphi_{y}^{J}\right. \\
& \left.+F_{y}^{Q} v_{P}+M_{x}^{Q} \varphi_{x}^{P}\right] \\
W_{z}^{B K}= & \frac{1}{2}\left(F_{z}^{B} w_{A}+F_{z}^{K} w_{J}+F_{z}^{Q} w_{P}\right)
\end{aligned}
$$

The total energy release is then computed by Eq. (4) as

$W^{\mathrm{TOT}}=\frac{1}{2} \sum_{i}^{5} F_{i}^{\mathrm{s}} u_{i}^{\mathrm{s}}+F_{i}^{\mathrm{a}} u_{i}^{\mathrm{a}}+F_{i}^{\mathrm{c}} u_{i}^{\mathrm{c}}$

where $i$ represents degree of freedom and $F_{i}^{\mathrm{s}}-u_{i}^{\mathrm{s}}$, $F_{i}^{\mathrm{a}}-u_{i}^{\mathrm{a}}$ and $F_{i}^{\mathrm{c}}-u_{i}^{\mathrm{c}}$ are generalised constraint forces and displacements at the steel plate, adhesive layer and composite patch, respectively. The associated area for the above energy is $A=\Delta a \cdot l$ where $l$ is the element depth in Fig. 4. Thus, the strain energy release rate, $G$, at the delamination front is obtained as

$G=\frac{W^{\mathrm{TOT}}}{A}$

The accuracy of such a calculation depends on the finite element mesh at the crack front. The procedure was validated in [24] with reference to a typical single-sided patch configuration [12].

\section{Finite element model}

The commercial finite element code ABAQUS ${ }^{\circledR}$ is used to perform the analyses by the three-layer technique. A schematic view of the reinforced plate geometry is shown in Fig. 5 [6-11].

Since composite strips are located on both sides of the plate, only one eighth of the specimen is meshed as a continuum medium using standard four-node two-dimensional elements (Fig. 6).

In particular, shell elements are used for the adhesive layer and composite patch while plane stress elements are used for the steel plate. According to experimental evidence, debond between the adhesive layer and the steel plate is assumed with a semi-elliptical shape (Fig. 5). The major semi-axis $b$ and the minor semi-axis $c$ are

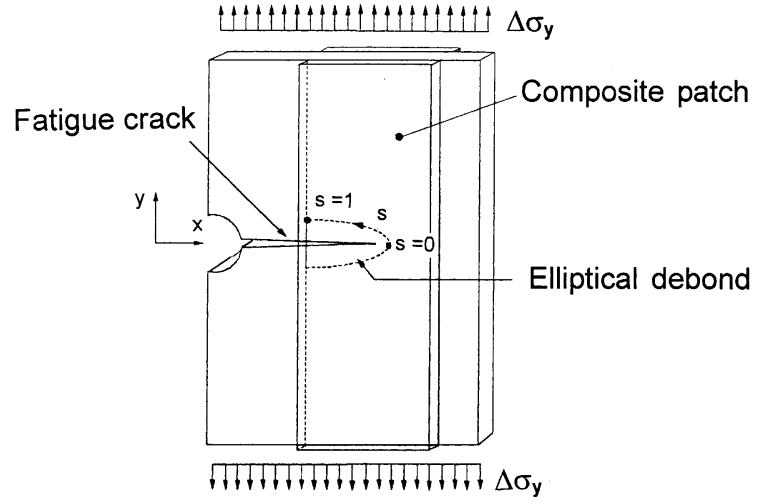

Fig. 5. Crack emanating from a rivet hole reinforced by composite patch.

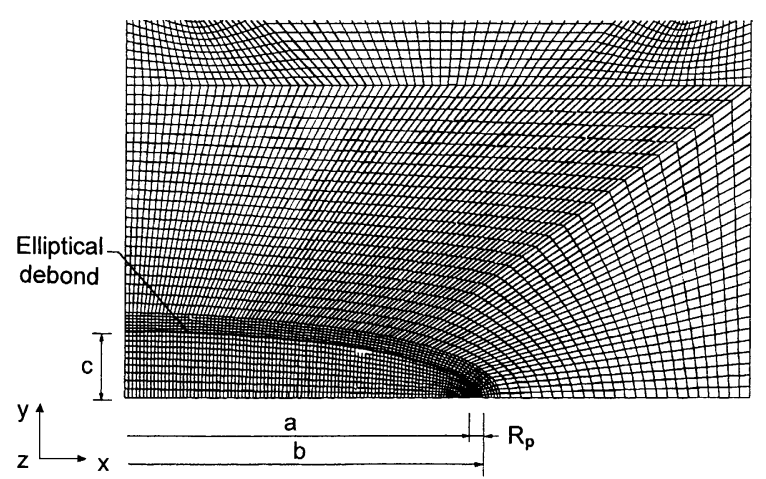

Fig. 6. Detail of the finite element model in the debonding region $(a=50 \mathrm{~mm})$.

$$
\begin{aligned}
& b=a-25+R_{\mathrm{p}} \\
& c=b / 5
\end{aligned}
$$

where $R_{\mathrm{p}}$ is the size of the plastic zone. The MVCCT according to the three-layer model is used to compute debond crack energy release rate. A parametric analysis is then performed in order to investigate the sensitivity of the adhesive-plate interface debond to variations in the composite thickness and Young's modulus in the fibres direction, adhesive thickness, pretension level and the size of the debonded region.

\section{Results and discussion}

A refined finite element mesh is required in the debonded region (Fig. 6) in order to achieve a 
regular behaviour of the $G$ distribution [24]. The pertinent parameters are $E_{1}=174 \mathrm{GPa}, h^{\mathrm{c}}=1.2$ $\mathrm{mm}, h^{\mathrm{a}}=0.3 \mathrm{~mm}$, an elliptical debonded region with $c / b$ equal to $1 / 5$ and no pretension $\left(\sigma_{\mathrm{p}}=0\right)$ in the composite strips. Reference is made to a crack length $a$ equal to $50 \mathrm{~mm}$ (Fig. 6). Results are presented in Figs. 7-9 and 11, always as function of the normalised arch length $s$ (defined in Fig. 5). The $G$ distribution corresponding to the reference parameters, which is reported in each figure by cross-points, has a relevant maximum value equal to $0.4 \mathrm{~N} / \mathrm{mm}$, see Fig. 7. The maximum stress $\sigma_{y, \max }$ in the steel plate is equal to $133 \mathrm{MPa}$ and produces a stress intensity factor in the steel plate equal to $1370 \mathrm{~N} / \mathrm{mm}^{3 / 2}$ for a crack length $a=50 \mathrm{~mm}[6$ 11]. The corresponding strain energy release rate $G$, under the plane stress hypothesis, is equal to $8.9 \mathrm{~N} / \mathrm{mm}$. As it can be seen, the debonded strain energy release rate is then much smaller than the corresponding value in the cracked steel plate. This shows that the contribution of debond crack to the strain energy release rate is marginal. Anyway, the extension of the debonded region is of practical importance since it influences the stress intensity factor level in the cracked steel plate as showed in [6-11].

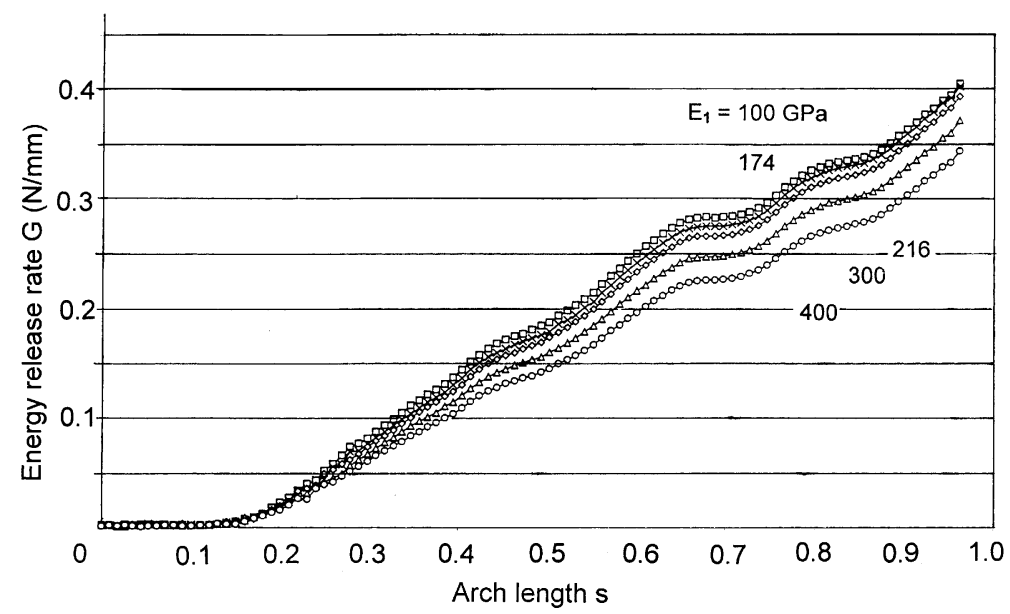

Fig. 7. Influence of composite patch Young's modulus $E_{1}$ on debond crack strain energy release rate.

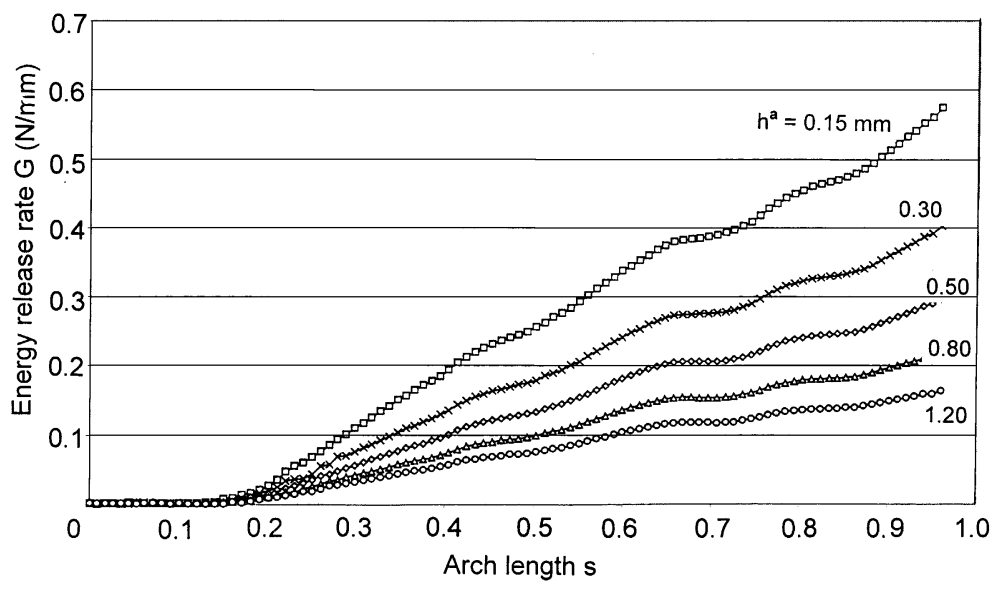

Fig. 8. Influence of adhesive thickness $h^{\mathrm{a}}$ on debond crack strain energy release rate. 


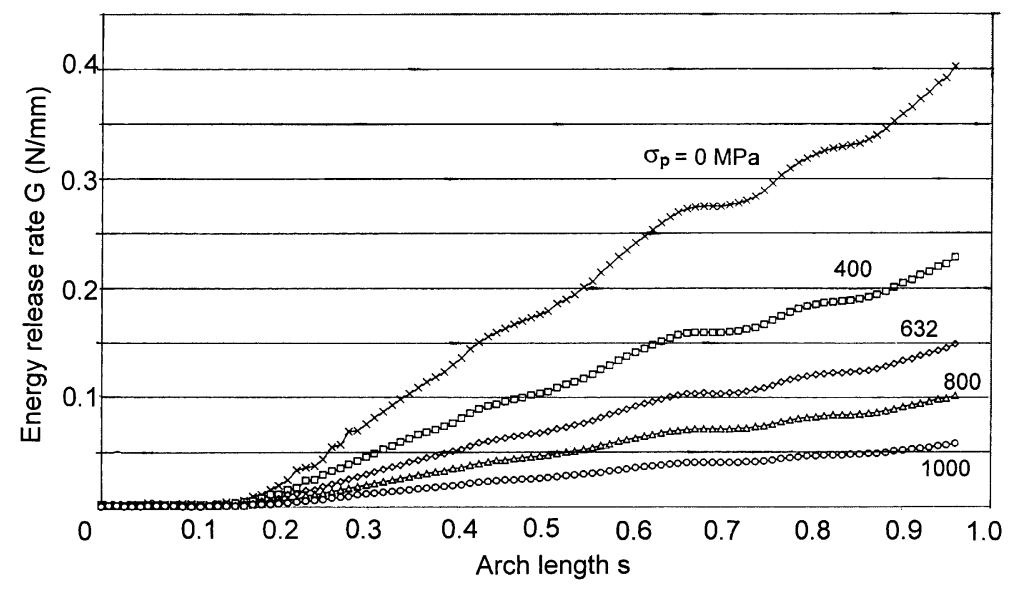

Fig. 9. Influence of pretension level $\sigma_{\mathrm{p}}$ on debond crack strain energy release rate.

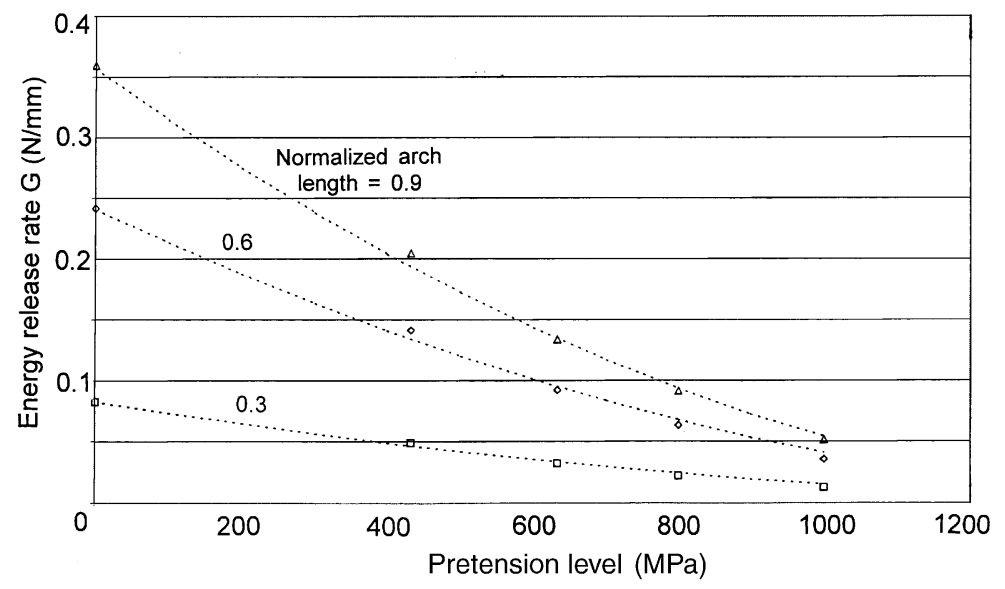

Fig. 10. Influence of the pretension level at different normalised arch lengths.

The goal of the following parametric study is to investigate the sensitivity of debond crack strain energy release rate $G$ to some design parameters such as the patch stiffness $\left(E_{1}\right.$ and $\left.h^{\mathrm{c}}\right)$, adhesive thickness $\left(h^{\mathrm{a}}\right)$ and the pretension level $\sigma_{\mathrm{p}}$. A variation of the patch stiffness can be achieved by changing either the patch thickness $h^{\mathrm{c}}$ or the patch Young's modulus $E_{1}$. Results show that the debond crack strain energy release rate is not strongly dependent from the patch stiffness (Fig. 7).

This is due to the high stiffness of the steel plate compared to the CFRP strips one. The increase of $E_{1}$ from 100 to $400 \mathrm{GPa}$ produces in fact a re- duction of $G$ that is confined to $12 \%$. In [6-11], it is reported that a corresponding increase of $E_{1}$ produces a $30 \%$ significant decrease of the stress intensity factor in the steel plate. Fig. 7 shows that near the steel plate crack tip the strain energy release rate approach zero. This indicates that the debond crack front is unlikely ahead of the plate crack. The increase of the patch thickness $h^{\mathrm{c}}$ does not produce any significant variation in the $G$ values distribution and therefore the corresponding plot is not given. In fact, the $h^{\mathrm{c}}$ increase produces an increase in the patch shear deformations, which reduces the positive effect connected to stiffness increase. Note that in [6-11], a moderate 


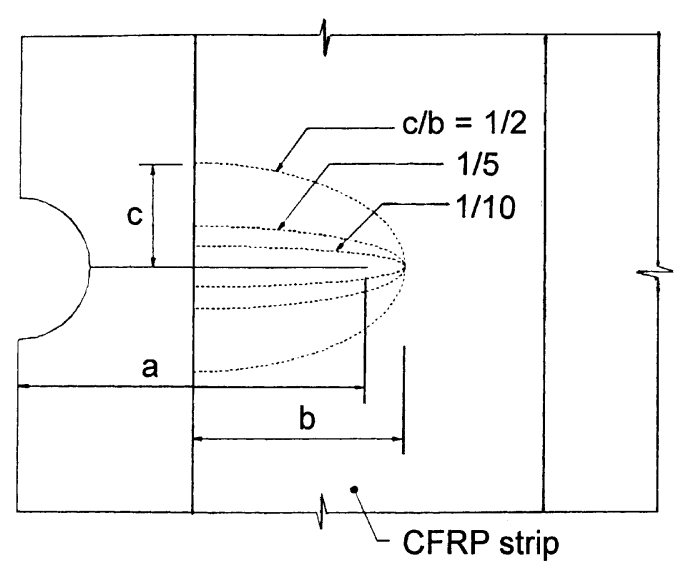

Fig. 11. Elliptical debonded region aspect ratios used in the parametric analysis.

$16 \%$ decrease of the stress intensity factor in the steel plate is achieved by increasing $h^{\mathrm{c}}$ from 1.0 to $2.0 \mathrm{~mm}$.

The adhesive thickness $h^{\mathrm{a}}$ is a very important parameter for the assessment of the effectiveness of the crack reinforcement (Fig. 8).

By increasing $h^{\mathrm{a}}$, the effectiveness is decreased due to shear deformation of the adhesive layer. As $h^{\mathrm{a}}$ is increased from 0.15 to $1.2 \mathrm{~mm}$, a drastic $72 \%$ decrease of the $G$ values at the debond crack is achieved, due to the reduction of the relative displacements at the interface. Note that in [6-11] a corresponding increase of the adhesive thickness produces a moderate $15 \%$ increase of the stress intensity factor in the steel plate. When a thinner adhesive layer is used, the debond crack energy release rate increases and a larger debonded region is then expected.

The $G$ distribution corresponding to different pretension level $\sigma_{\mathrm{p}}$ is reported in Fig. 9.

A drastic $87 \%$ reduction of the $G$ values is achieved by increasing the pretension level from 0 to $1000 \mathrm{MPa}$. Numerical results show that the relationship between $\sigma_{\mathrm{p}}$ and the interface relative displacements and forces is linear. This means that the pretension can be considered as a compressive load applied to the steel plate. Under this hypothesis the pretension effect on crack reinforcement can then be related to the $G$ distribution for $\sigma_{\mathrm{p}}=0$. In Fig. 10, the debond crack strain energy release rate as a function of the pretension level $\sigma_{\mathrm{p}}$ is reported, for three different normalised arch lengths ( $s=0.3, s=0.6, s=0.9$ ).

Since the relationship between the relative displacements and forces at the interface is linear, $G$ in Eqs. (12) and (13) is a quadratic function of $\sigma_{\mathrm{p}}$. This is indicated in Fig. 10 by superimposed curve fitting or, in other words, by drawing second order parabolas that best fit with the data points. Note that prestress does not produce any variation of the stress intensity factor range in the steel plate but reduces the stress ratio and then promote crack closure [20]. This clearly shows the fundamental contribution of pretension to the effectiveness of the patch reinforcement of steel elements.

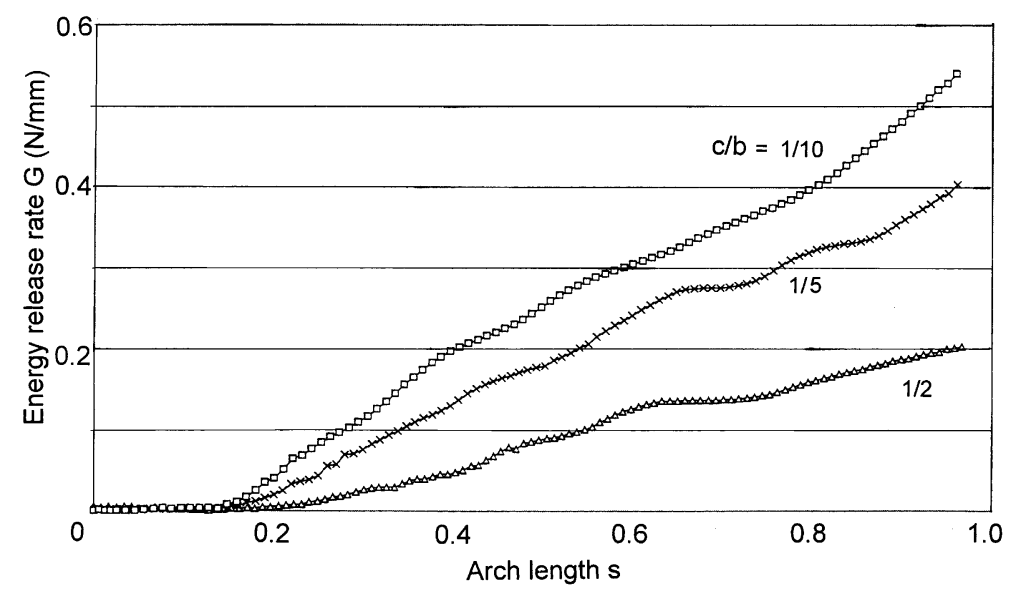

Fig. 12. Influence of the debond aspect ratio $c / b$ on debond crack strain energy release rate. 
Finally, the size of debonded region has a significant influence on the effectiveness of the crack reinforcement. On the basis of experimental findings, an elliptical debonded region (Fig. 11) with $c / b=1 / 5$ is assumed as reference value in the numerical analysis.

By increasing the debonded area, the effectiveness of the crack reinforcement is decreased due to the reduction of the load transfer from the steel plate to the composite strips. A $78 \%$ reduction of $G$ values is then obtained by increasing the aspect ratio $c / b$ from $1 / 10$ to $1 / 2$ (Fig. 12). This means that the debonded area is expected to be limited to a region close to the steel plate crack (Fig. 11), i.e. with a low $c / b$ ratio.

Note that in [6-11] an increase of $c / b$ from $1 / 10$ to $1 / 2$ produces a $20 \%$ increase of the stress intensity factor in the steel plate. It shows that the size of the debonded region has a significant influence on both the stress intensity factor level in the cracked steel plate and the effectiveness of the repair.

\section{Conclusions}

Numerical analyses were performed with reference to crack patching tests carried out in order to evaluate debond crack strain energy release rate, $G$, and to investigate the influence of some design parameters on the $G$ distribution. The threelayer modelling technique is adopted in connection with the MVCCT to reduce the computational effort.

For the investigated steel elements reinforced by prestressed composite strips, it can be concluded that debond is not a dominant failure mode. This is due to the high stiffness of the steel plate that produces low debond strain energy release rate values at the debond front. The high stiffness of the steel plate compared to the composite strips reduces the influence of the CFRP stiffness on the $G$ distribution as clearly indicated in Fig. 7 . Therefore, the use of very stiff CFRP strips does not produce a significant increase of the effectiveness of the reinforcement.

An increase in adhesive thickness produces an increase in adhesive layer shear deformation, which drastically reduces the $G$ values on the debond front (Fig. 8). Note that a corresponding moderate increase of the stress intensity factors in the steel plate can be seen. Therefore, it can be concluded that a thin adhesive layer produces a larger debonded area, which in return reduces the effectiveness of the reinforcement.

The application of a pretension to the composite strips prior to bonding produces a significant decrease of the distribution of $G$ values along the debond front (Fig. 9). Note that a corresponding drastic reduction of the stress ratio in the steel plate is achieved, which promotes crack closure. Therefore, it can be concluded that pretension is strongly recommended in order to maximise the effectiveness of the bonded patch on steel section.

There is also the fundamental issue whether the MVCCT associated with energy release would be valid if the virtual displacement is not compatible with the natural crack extension direction in reality. This raises the question whether the corresponding virtual work would be a true minimum. That is the crack growth in mode II is being mathematically forced to extend in a direction different from that occurs in nature. The strain energy density criterion $[17,18]$ does not have such a limitation and will be used in the future to examine the difference in the results.

\section{Acknowledgements}

The financial support to the first author by the Italian Ministry of Instruction, University and Research (MIUR) and to the second and third authors by the Swiss National Science Foundation and EPFL Lausanne is gratefully acknowledged. Thanks are also expressed to Prof. Manfred A. Hirt, director of ICOM, to Sika AG-Zürich for supplying composite materials and to $\mathrm{Mr}$. Paolo Barichello for the computational help.

\section{References}

[1] A.A. Baker, R. Jones, Bonded Repair of Aircraft Structures, Martinus Nijhoff Publishers, 1988. 
[2] T.V.R.S. Umamaheswar, R. Singh, Modelling of patch repair to a thin cracked sheet, Engineering Fracture Mechanics 62 (1999) 267-289.

[3] U. Meier, Carbon fibre-reinforced polymers: modern materials in bridge engineering, Structural Engineering International 1 (1992) 7-12.

[4] M. Deuring, Verstärken von Stahlbeton mit Gespannten Faserverbund-Werkstoffen (in German), Report 224, Swiss Federal Laboratories for Materials Testing and Research, EMPA, 1993.

[5] N. Ammar, Rehabilitation of steel bridge girders with graphite pultrasion, CCM Report 96-26, Center for Composite Materials, University of Delaware, 1996.

[6] A. Bassetti, A. Nussbaumer, M. Hirt, Crack repair and fatigue life extension of riveted bridge members using composite materials, in: Bridge Engineering Conference (IABSE), Sharm El-Sheikh, Egypt, vol. 1, 2000, pp. 227238.

[7] A. Bassetti, P. Colombi, A. Nussbaumer, Finite element analysis of steel members repaired by prestressed composite patch, in: IGF2000, Bari, Italy, 2000, CD-ROM.

[8] A. Bassetti, A. Nussbaumer, P. Colombi, Repair of riveted bridge members damaged by fatigue using CFRP materials, in: Advanced FRP Materials for Civil Structures, Bologna, Italy, 2000, pp. 33-42.

[9] A. Bassetti, A. Nussbaumer, A. Hirt, Fatigue life extension of riveted bridge members using prestressed carbon fibre composites, in: Steel Structures of the 2000's, ECCS, Istanbul, Turkey, 2000, pp. 375-380.

[10] A. Bassetti, Lamelles Précontraintes en Fibres Carbone pour le Renforcement de Ponts Rivetés Endommaées par Fatigue (in French), Ph.D. Thesis no. 2440, Swiss Federal Institute of Technology, EPFL, Lausanne, 2001.

[11] A. Bassetti, M. Facchini, P. Jacquot, Amélioration de la tenue en fatigue de structures métalliques: évaluation par interférométrie speckle du procédé de renforcement par lamelles composites (in French), in: Photomécanique 2001, Poiters, France, 2001, pp. 351-358.
[12] C.T. Sun, J. Klug, C. Arendt, Analysis of cracked aluminium plates repaired with bonded composite patches, AIAA Journal 54 (1996) 369-374.

[13] S. Naboulsi, S. Mall, Modelling of a cracked metallic structure with bonded composite patch using the three layer technique, Composite Structures 35 (1996) 295-308.

[14] C.T. Sun, C.J. Jih, On strain energy release rates for interfacial cracks in bi-material media, Engineering Fracture Mechanics 28 (1987) 13-20.

[15] C.T. Sun, W. Qian, The use of finite extension strain energy release rates in fracture of interfacial cracks, International Journal of Solids and Structures 34 (1997) 2595-2609.

[16] D.R. Mulville, P.W. Mast, Strain energy release rate for interfacial cracks between dissimilar media, Engineering Fracture Mechanics 8 (1976) 555-565.

[17] G.C. Sih, T.B. Hong, Integrity of edge-debonded patch on cracked panel, Journal of Theoretical and Applied Fracture Mechanics 12 (1989) 121-139.

[18] G.C. Sih, Fracture and failure analysis: assessment on integrity of repaired structure by composite patching, in: Advanced Composites in Engineering Technology, Athens, Greece, 1991, pp. 45-90.

[19] E.F. Rybicki, M.F. Kanninen, A finite element calculation of stress intensity factors by a modified crack closure integral, Engineering Fracture Mechanics 9 (1977) 931938.

[20] S. Suresh, Fatigue of Materials, Cambridge University Press, 1991.

[21] G. Cloud, Optical Methods in Engineering Analysis, Cambridge University Press, 1995.

[22] M.M. Ratwani, Analysis of cracked adhesively bonded laminated structures, AIAA Journal 17 (1979) 988-994.

[23] S. Zheng, C.T. Sun, A double-plate finite-element model for the impact-induced delamination problem, Composite Science and Technology 53 (1995) 111-118.

[24] P. Barichello, Analisi di Elementi Metallici con Rinforzi in Fibra di Carbonio (in Italian), Master Thesis, Technical University of Milan, 2001. 